\title{
Successful Vaginal Delivery after Induction of Labour in a Patient Treated for Non-Hodgkin's Lymphoma of the Cervix: A Case Report and Literature Review
}

\author{
Paola Quaresima ${ }^{D},{ }^{1}$ Gabriele Saccone, ${ }^{2}$ Valeria Zuccalà, ${ }^{3}$ Giuseppe Guarascio, ${ }^{4}$ Livio Leo, ${ }^{5}$ \\ Giuseppina Amendola, ${ }^{1}$ Fulvio Zullo, ${ }^{1}$ Michele Morelli, ${ }^{6}$ and Roberta Venturella ${ }^{1}$ \\ ${ }^{1}$ Unit of Obstetrics and Gynaecology, "Magna Graecia" University, Catanzaro, Italy \\ ${ }^{2}$ Department of Neuroscience, Reproductive Science and Dentistry, School of Medicine, University of Naples Federico II, Naples, Italy \\ ${ }^{3}$ Department of Anatomic Pathology, "Pugliese Ciaccio" Hospital, Catanzaro, Italy \\ ${ }^{4}$ Department of Radiology, "Pugliese Ciaccio" Hospital, Catanzaro, Italy \\ ${ }^{5}$ Department of Obstetrics and Gynecology Beauregard Hospital, AUSL Valle D'Aosta, Italy \\ ${ }^{6}$ Complex Operative Structure Obstetrics and Gynaecology, Annunziata Hospital, Cosenza, Italy
}

Correspondence should be addressed to Paola Quaresima; dr.paolaquaresima@gmail.com

Received 20 December 2021; Accepted 27 January 2022; Published 10 February 2022

Academic Editor: Maria Grazia Porpora

Copyright (c) 2022 Paola Quaresima et al. This is an open access article distributed under the Creative Commons Attribution License, which permits unrestricted use, distribution, and reproduction in any medium, provided the original work is properly cited.

\begin{abstract}
Objective. Primary non-Hodgkin's lymphomas of the cervix are rare; they represent about $1 \%$ of all cases. There are no available guidelines regarding the safest mode of delivery after treatment and resolution of a cervical lymphoma. Case Report. We report the first case of a successful vaginal delivery after induction of labour in a woman recovered from a primary large B-cell lymphoma of the cervix and a literature review. Conclusion. In carefully selected patients with fully treated non-Hodgkin's lymphoma of the cervix with no residual disease, induction of labour via prostaglandins pessary may be a safe option if indicated.
\end{abstract}

\section{Introduction}

Primary non-Hodgkin's lymphomas of the cervix are a rare finding, representing about $1 \%$ of all cases of non-Hodgkin's lymphoma [1]. Among different subtypes, large B-cell lymphoma (LBCL) is the most common primarily involving the lower uterine segment $[2,3]$. There are no available guidelines on the mode of delivery for women treated for a cervical lymphoma, and few cases have been described about [4-8]. We report the first case of a successful vaginal delivery after induction of labour in a woman recovered from a primary large Bcell lymphoma of the cervix.

\section{Case Report}

A 30-year-old nulliparous Caucasian woman presented with a history of dysfunctional uterine bleeding lasting for six months. The patient did not report any past or present significant medical history. Blood analysis was within the normal range, with white blood cells $6000 \mathrm{U} / \mathrm{L}$, haemoglobin concentration $13 \mathrm{~g} / \mathrm{dL}$, haematocrit of $33 \%$, and platelet count $165 \times 10^{3} / \mu \mathrm{l}$. The last smear test, performed 24 months before, was negative for neoplasia. At the transvaginal evaluation, the cervix appeared to be irregular due to the presence of a $5 \mathrm{~cm}$ diameter mass. The patient underwent hysteroscopy, with a fractional curettage and cervical biopsies. Endometrial and endocervical curettage revealed benign glandular tissue, but cervical biopsies demonstrated a diffuse large B-cell lymphoma (LBCL). The immunohistochemical evaluation of the cervical lesion biopsy was positive for Bcell markers (CD20+, CD10+, BCL6+, and PAX5+), as shown in Figure 1.

Both a computed tomography (CT) and a magnetic resonance image (MRI) demonstrated the presence of a cervical 


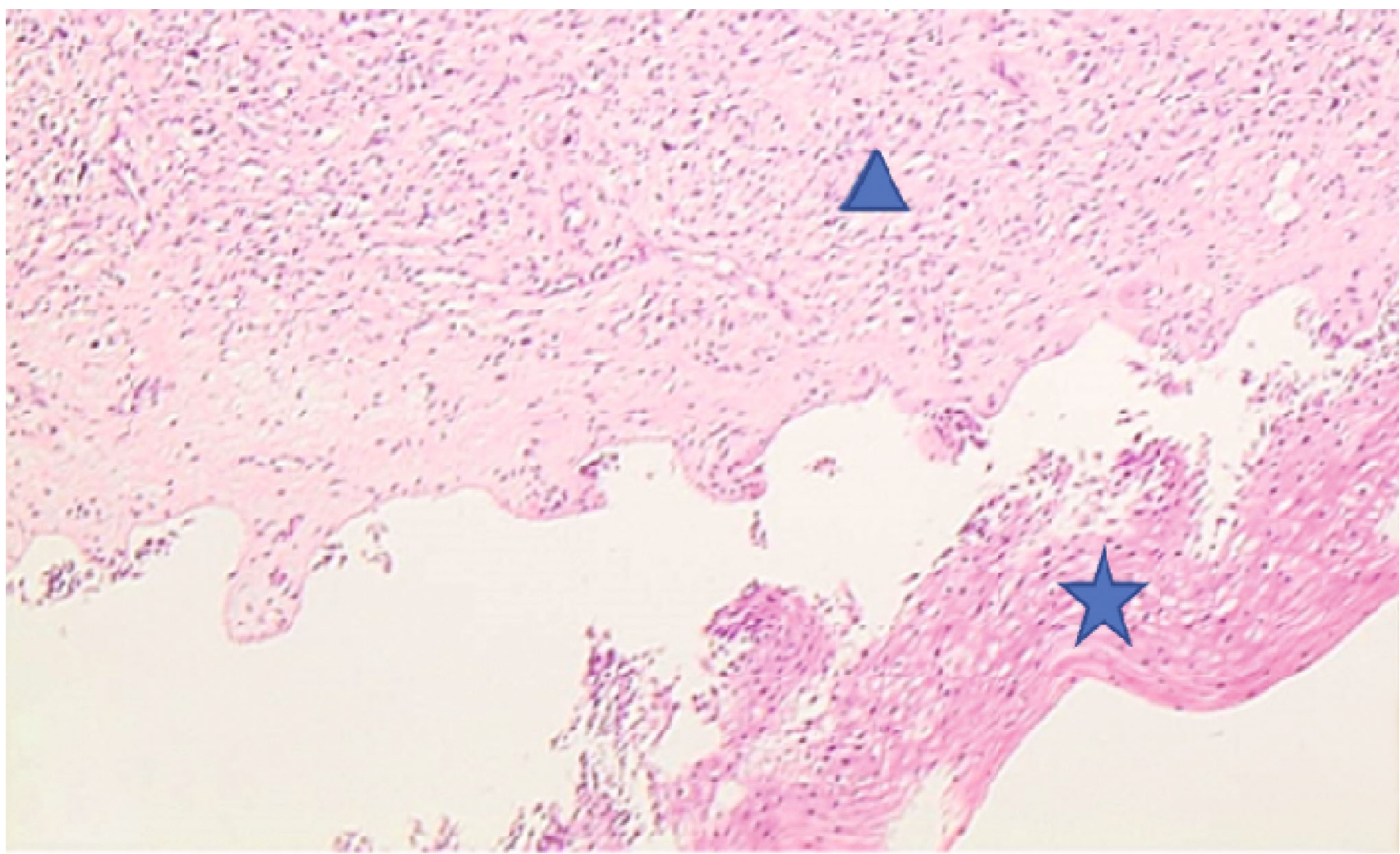

(a)

Figure 1: Continued. 


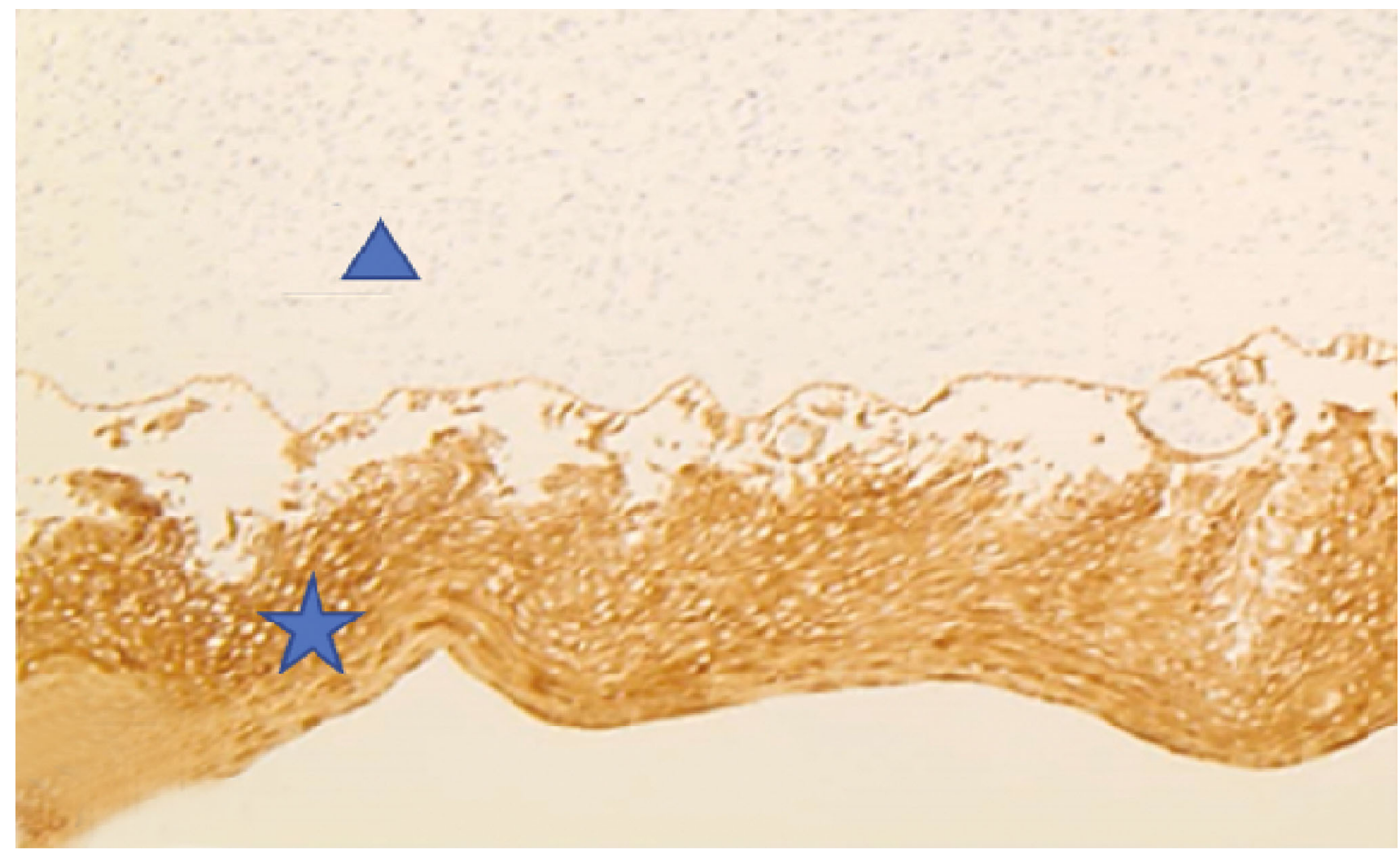

(b)

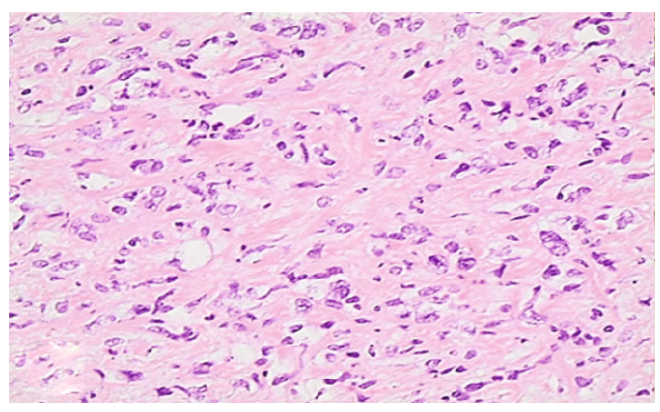

$\triangle$ Sub-mucosal lymphoid neoplastic proliferation

$\hat{\omega}$ Normal esocervical epithelium

(c)

Figure 1: Continued. 


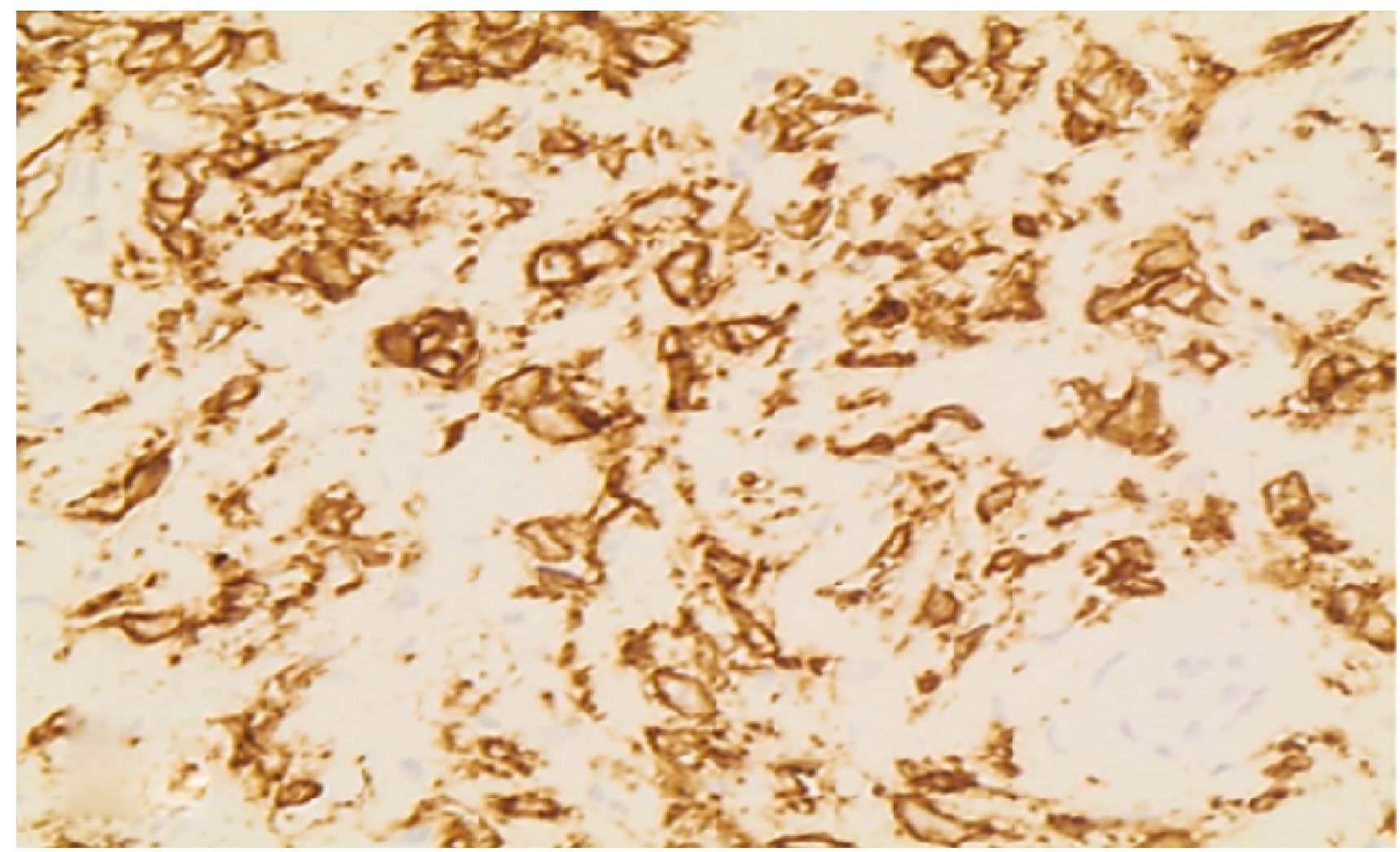

(d)

Figure 1: Pathology examination. (a) EE 4x; (b) 4x, immunohistochemical for CK, AE1-AE3: esocervical epithelium is strongly positive; (c) EE 10x, diffuse proliferation of large lymphoid cells with fibrous stromal reaction; (d) 10x, immunohistochemical for CD20: large lymphoid cells are strongly positive.

mass without extra pelvic lesions. A positron emission tomography (PET) revealed mild uptake of the radioactive tracer at the low uterus level. Following completion of staging studies, the woman was referred to the oncology team, who staged the patient's tumour as IE-B, one extra lymphatic site without fever, night sweats, or weight loss (Ann Arbor staging system). Eight cycle courses of chemotherapy and immunotherapy were recommended. The treatment protocol was based on the combination of: $\mathrm{CHOP}+$ Rituximab (Cyclophosphamide, Doxorubicin, Vincristine, Dexamethasone, and Rituximab). Before chemotherapy, depot Leuprolide $11.25 \mathrm{mg}$ intramuscular injection was given every 12 weeks to preserve future fertility against potential chemotherapy's side effects. Six months after completion of medical treatment, a transvaginal ultrasound revealed resolution of the cervical lesion, and follow-up cervical biopsies did not reveal residual disease. PET, CT, and MRI revealed a complete resolution of the cervical lesion. Pre and posttreatment MRI are available in Figure 2. One year after completion of chemotherapy, the patient conceived spontaneously. The pregnancy was uneventful, and at 41 weeks of gestation, according to national guidelines, an induction of labour for postterm pregnancy was offered to the women. Her Bishop score, for cervical evaluation prior to the induction of labour, was calculated and resulted to be 2 (firm, closed, posterior, $50 \%$ effaced cervix with a minus two head station); therefore, a Prostaglandin E2 pessary
(Propess, Ferring SPA) was introduced into the vaginal posterior fornix. Active labour started at 24 hours from the protocol beginning, and a healthy female of $3100 \mathrm{~g}$ was delivered at 36 hours. Cervix dilated and effaced regularly; no cervical trauma was reported. A case report summary is available in Table 1.

\section{Discussion}

Primary non-Hodgkin's lymphomas of the cervical stroma are localized at the level of the cervix without any involvement of the myometrium or evidence for leukaemia at the time of diagnosis [9].

A primary cervical involvement by a lymphoma is a rare finding. Among subtypes, large B-cell is the most common non-Hodgkin's lymphoma of the cervix, representing approximately $31 \%$ of cases [10]. Affected women usually present with symptoms such as abnormal vaginal bleeding, dyspareunia, and/or pelvic pain, whereas for fever, night sweats, and weight loss, traditional lymphoma symptoms are uncommon [4-7]. The appropriate management starts with a cervical biopsy with pathological immunephonotypical evaluation, to differentiate cervical nonHodgkin's lymphoma from benign and malignant disease of the cervix. Papanicolaou testing is usually of any help in the diagnosis of cervical lymphomas due to the subepithelial location of the abnormal cells [11]. CT and PET are crucial 


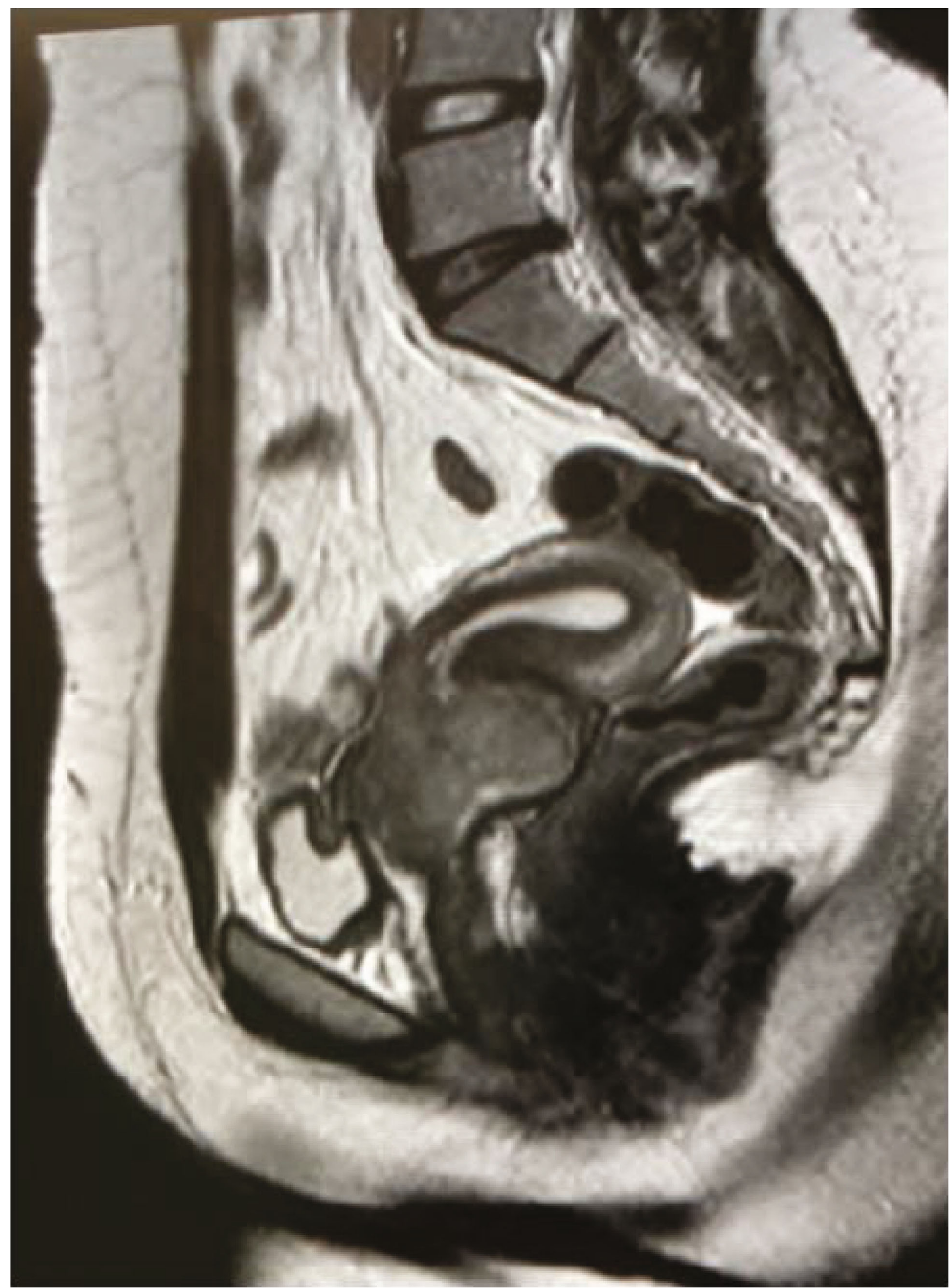

(a)

Figure 2: Continued. 


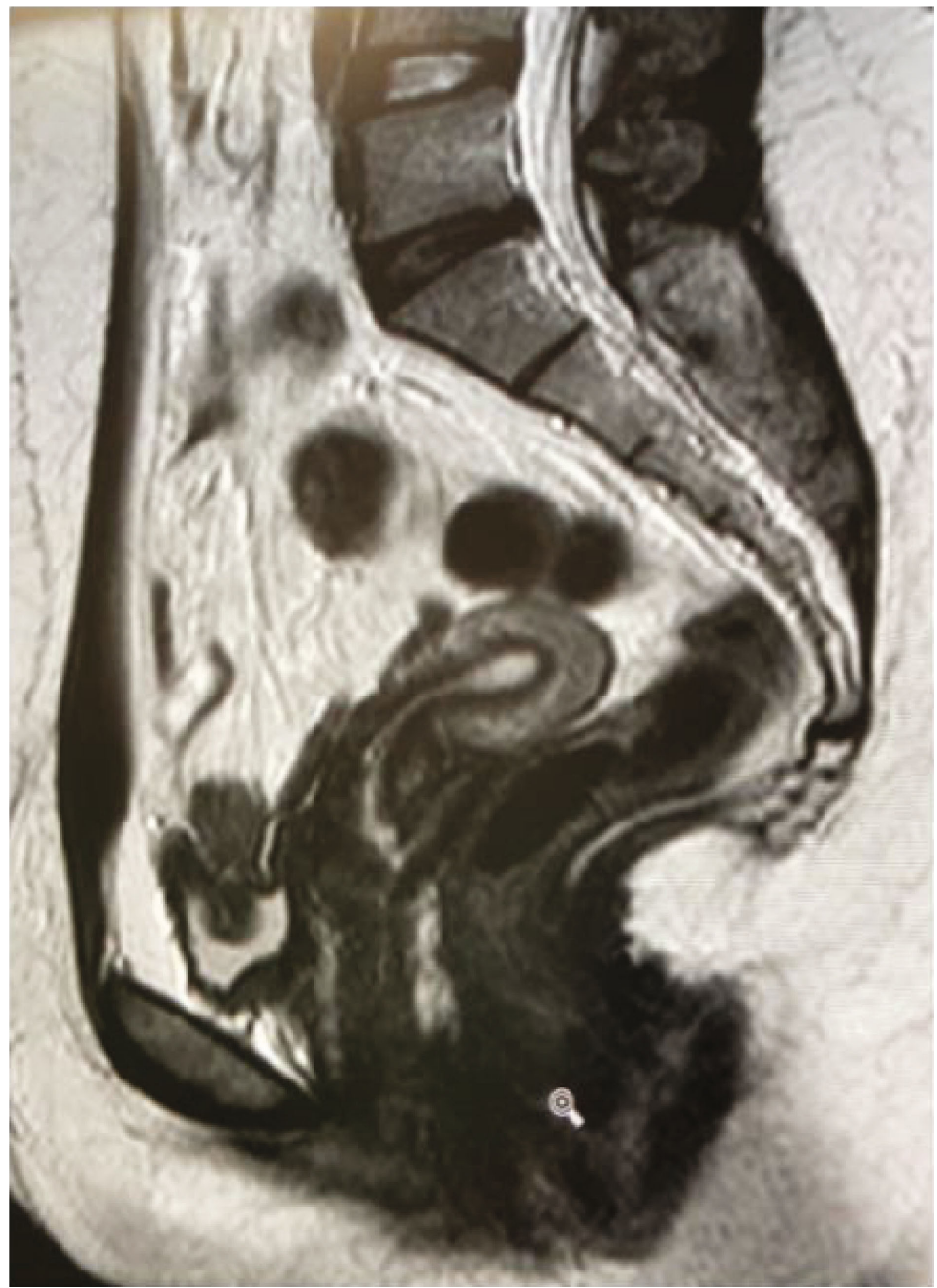

(b)

FIGURE 2: Magnetic resonance T2 weighted images. (a) Low uterine segment appearance at diagnosis. (b) Low uterine segment appearance after treatment. 
TABLE 1: Case report summary.

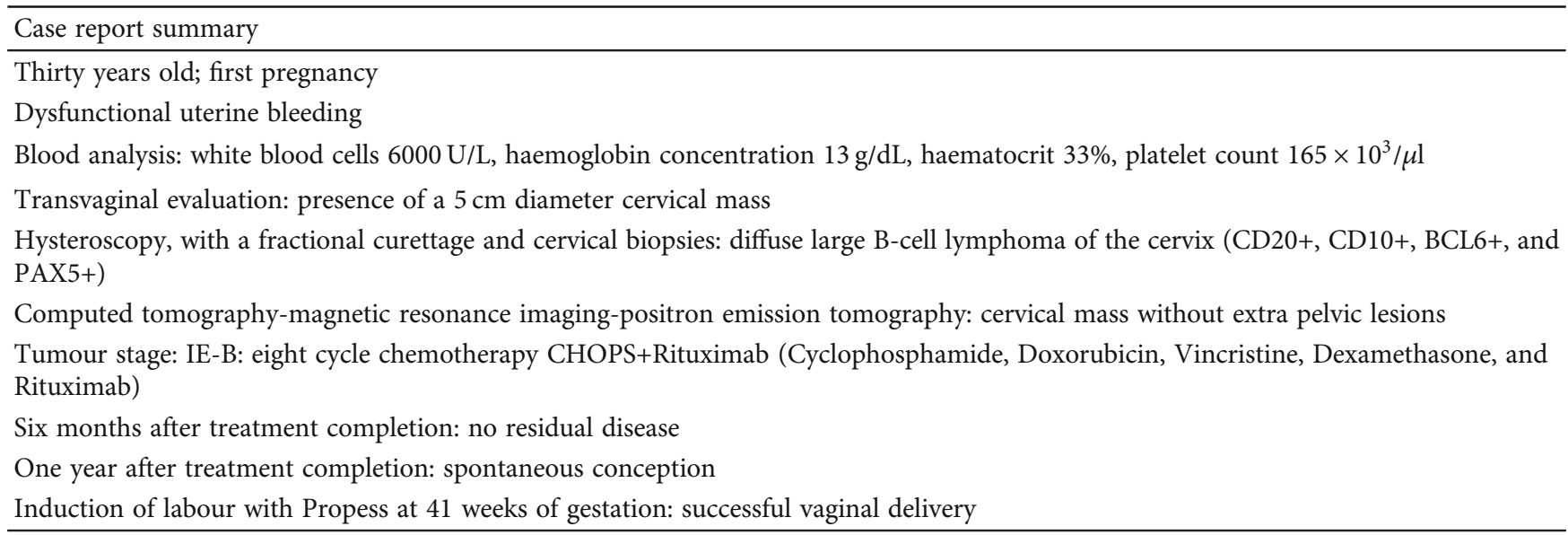

TABLE 2: Mode of delivery in women affected by cervical lymphoma, literature review.

\begin{tabular}{|c|c|c|c|c|}
\hline & $\begin{array}{l}\text { Literature } \\
\text { review }\end{array}$ & Mode of delivery & Lymphoma treatment & Cervical lymphoma status \\
\hline 1 & $\begin{array}{l}\text { Sandvei et al. } \\
1990[4]\end{array}$ & Caesarean section: narrow pelvis & Chemotherapy & $\begin{array}{c}\text { Two years after resolution of the cervical } \\
\text { lymphoma }\end{array}$ \\
\hline 2 & $\begin{array}{l}\text { Wang et al. } 1999 \\
\text { [5] }\end{array}$ & $\begin{array}{c}\text { Caesarean section: arrest of cervical } \\
\text { dilatation }\end{array}$ & Unavailable & $\begin{array}{l}\text { Lymphoma diagnosed during } \\
\text { pregnancy }\end{array}$ \\
\hline 3 & $\begin{array}{l}\text { Lorusso et al. } \\
\quad 2007[6]\end{array}$ & $\begin{array}{l}\text { Caesarean section: cervical } \\
\text { lymphoma treatment }\end{array}$ & $\begin{array}{l}\text { Surgery: cold knife conization and } \\
\text { chemotherapy }\end{array}$ & $\begin{array}{l}\text { Three years after resolution of the } \\
\text { cervical lymphoma }\end{array}$ \\
\hline 4 & $\begin{array}{l}\text { Ferreri et al. } \\
2008[7]\end{array}$ & Vaginal delivery & Chemotherapy and radiotherapy & $\begin{array}{c}\text { Three years after resolution of the } \\
\text { cervical lymphoma }\end{array}$ \\
\hline 5 & $\begin{array}{l}\text { Parva et al. } 2010 \\
{[8]}\end{array}$ & Vaginal delivery & Chemotherapy & $\begin{array}{l}\text { Five years after resolution of the cervical } \\
\text { lymphoma }\end{array}$ \\
\hline 6 & $\begin{array}{l}\text { Current case } \\
2021\end{array}$ & $\begin{array}{c}\text { Induction of labour with vaginal } \\
\text { delivery }\end{array}$ & Chemotherapy & $\begin{array}{c}\text { One year after resolution of the cervical } \\
\text { lymphoma }\end{array}$ \\
\hline
\end{tabular}

to determinate the extension of disease [12]. Both the FIGO and the Ann Arbor staging systems are used for extra nodal lymphomas [13].

Management with chemotherapy and immunotherapy reduces the need for radiotherapy or surgical resection, particularly for women during childbirth age $[14,15]$. Current chemotherapy regimens are safe and can spare fertility, particularly when GnRH agonists (Leuprolide) are used in conjunction with treatment [15-18], although oocyte cryopreservation can be proposed in some cases.

There are no available guidelines regarding the safest mode of delivery after treatment for a cervical B-cell lymphoma. There is occurrence of potential complications such as pelvic outlet obstruction or potential lower uterine segment rupture (due to incomplete resolution of the disease or architectural changes after radiations, let the mode of delivery become an argument of discussion) [4-8]. Indeed, the available literature regarding the mode of delivery for patient affected by a cervical lymphoma reports that only two out of the five previously reported cases experienced a successfully vaginal delivery $[7,8]$. One out of three cases delivered via caesarean section received a specific indication due to the previ- ously treated cervical lymphoma [6]. All but one pregnancy occurred at least two years after resolution of the disease, and only one has been diagnosed during pregnancy [5]. Almost all cases have been treated with chemotherapy (4/5), one out of five also received a surgical treatment (cold knife conization) [6], and one also received radiotherapy [7]. No delivery complications have been reported. A description of the five previously reported cases is available in Table 2 . Induction of labour has been never described after a treatment for a cervical lymphoma; our case is therefore unique.

\section{Conclusions}

In carefully selected patients with fully treated nonHodgkin's lymphoma of the lower uterine segment and cervix with no apparent disease, induction of labour via prostaglandins pessary may be a safe option in case of indication.

\section{Data Availability}

The used to support the findings of this study are available from the corresponding author upon request. 


\section{Consent}

The patient gave her written consent for publication.

\section{Conflicts of Interest}

The authors declare that they have no conflicts of interest.

\section{References}

[1] A. F. Korcum, I. Karadogan, G. Aksu et al., "Primary follicular lymphoma of the cervix uteri: a review," Annals of Hematology, vol. 86, pp. 623-630, 2007.

[2] J. Rittenbach, J. D. Cao, L. M. Weiss et al., "Primary diffuse large B-cell lymphoma of the uterus presenting solely as an endometrial polyp," International Journal of Gynecological Pathology, vol. 24, pp. 347-351, 2005.

[3] N. V. Frey, J. Svoboda, C. Andreadis et al., "Primary lymphomas of the cervix and uterus: the University of Pennsylvania's experience and a review of the literature," Leukemia \& Lymphoma, vol. 47, pp. 1894-1901, 2006.

[4] R. Sandvei, K. Lote, E. Svendsen et al., "Successful pregnancy following treatment of primary malignant lymphoma of the uterine cervix," Gynecologic Oncology, vol. 38, pp. 128-131, 1990.

[5] P. H. Wang, K. C. Chao, G. Lin, H. T. Chao, C. C. Yuan, and H. T. Ng, "Primary malignant lymphoma of the cervix in pregnancy. A case report," A case reports. J Reprod Med, vol. 44, no. 7, pp. 630-632, 1999.

[6] D. Lorusso, G. Ferrandina, L. Pagano, M. L. Gagliardi, and G. Scambia, "Successful pregnancy in stage IE primary nonHodgkin's lymphoma of uterine cervix treated with Neoadjuvant chemotherapy and conservative surgery," Oncology, vol. 72, no. 3-4, pp. 261-264, 2008.

[7] A. J. Ferreri, C. Verona, A. Bolognesi, G. Taccagni, M. Ponzoni, and S. Ferrari, "Successful pregnancy after chemo-immuno-radiation therapy for aggressive lymphoma of the uterus," British Journal of Haematology, vol. 142, no. 1, pp. 141-143, 2008.

[8] M. Parva, K. Lamb, D. C. Savior, P. Gilman, and M. Belden, "Full-term pregnancy and vaginal delivery after treatment for non-Hodgkin's lymphoma of the cervix and lower uterine segment: a case report," Journal of Obstetrics and Gynaecology Canada, vol. 336, pp. 620-624, 2011, PMID: 21846452.

[9] N. L. Harris and R. E. Scully, "Malignant lymphoma and granulocytic sarcoma of the uterus and vagina. A clinicopathologic analysis of 27 cases," Cancer, vol. 53, pp. 2530-2545, 1984.

[10] M. Van de Rijn, O. W. Kamel, P. P. Chang et al., "Primary lowgrade endometrial B-cell lymphoma," The American Journal of Surgical Pathology, vol. 21, pp. 187-194, 1997.

[11] A. Grace, N. O'Connell, P. Byrne et al., "Malignant lymphoma of the cervix. An unusual presentation and a rare disease," European Journal of Gynaecological Oncology, vol. 20, no. 1, pp. 26-28, 1999.

[12] J. H. Heeren, A. M. Croonen, and J. M. Pijnenborg, "Primary extranodal marginal zone B cell lymphoma of the female genital tract: a case report and literature review," International Journal of Gynecological Pathology, vol. 27, pp. 243-246, 2008.

[13] T. A. Lister, D. Crowther, S. B. Sutcliffe et al., "Report of a committee convened to discuss the evaluation and staging of patients with Hodgkin's disease: Cotswold's meeting," Journal of Clinical Oncology, vol. 7, pp. 1630-1636, 1989.
[14] N. X. Von der Weid, "Adult life after surviving lymphoma in childhood," Support Care Cancer, vol. 16, pp. 339-345, 2008.

[15] Z. Blumenfeld, "Gender difference: fertility preservation in young women but not in men exposed to gonadotoxic chemotherapy," Minerva Endocrinologica, vol. 32, pp. 23-34, 2007.

[16] R. I. Fisher, E. R. Gaynor, S. Dahlberg et al., "Comparison of a standard regimen (CHOP) with three intensive chemotherapy regimens for advanced non-Hodgkin's lymphoma," The New England Journal of Medicine, vol. 328, pp. 1002-1006, 1993.

[17] M. Signorelli, A. Maneo, S. Cammarota et al., "Conservative management in primary genital lymphomas: the role of chemotherapy," Gynecologic Oncology, vol. 104, pp. 416-421, 2007.

[18] O. Akbayir, K. Gungorduk, A. Gulkilik et al., "Successful treatment of primary vaginal diffuse large B-cell lymphoma using chemotherapy," Taiwanese Journal of Obstetrics \& Gynecology, vol. 47, pp. 334-337, 2008. 